\title{
Las valoraciones éticas de dos prácticas zooturísticas en México: cuestiones sobre geografia de los animales
}

\author{
Gino Jafet Quintero-Venegas 1 \\ Perla Tania Rosales-Estrada ${ }^{2}$
}

\begin{abstract}
Resumen: En México, al burro (Equus africanus asinus), se le ha mercantilizado como animal de trabajo y recurso turístico, y su imagen se ha vuelto parte del patrimonio y de la identidad colectiva en al menos dos localidades. Por un lado, el burro-cebra ha sido pintado con rayas para simular una cebra africana y está amarrado a una carreta para que los turistas que visitan Tijuana se fotografíen vestidos con un poncho mexicano y con un sombrero tradicional para llevarse un suvenir de esta ciudad fronteriza. En la Feria del Burro en Otumba, los burros son los protagonistas de diferentes espectáculos y deportes que refuerzan las relaciones de dominio entre humanos y animales. Este artículo, elaborado a partir de métodos y técnicas cualitativas, revela la construcción de los burros como recursos zooturísticos y las implicaciones éticas de esta construcción social dada la mercantilización de estos animales no humanos.
\end{abstract}

Palabras clave: zooturismo; animales no humanos; patrimonio; ética animal; geografía de los animales.

\section{As avaliações éticas de duas práticas zooturísticas no México: questões sobre geografia dos animais}

Resumo: No México, o burro (Equus africanus asinus) foi comercializado como animal de trabalho e recurso turístico, e sua imagem tornou-se parte do patrimônio e da identidade coletiva em pelo menos dois locais. Por um lado, a zebra-burro foi pintada com listras para simular uma zebra africana e é amarrada a um carrinho para que os turistas que visitam Tijuana sejam fotografados vestidos com um poncho mexicano e com um chapéu tradicional para tirar uma lembrança desta cidade fronteira. Na Donkey Fair em Otumba, os burros são protagonistas de diferentes shows e esportes que reforçam a relação entre humanos e animais. O objetivo deste artigo, elaborado a partir de métodos qualitativos, é revelar a construção de burros como recursos zooturísticos e as implicações éticas dessa construção social, dada a mercantilização desses animais não humanos.

Palavras-chave: zooturismo; animais não humanos; patrimônio; ética animal; geografia animal.

\section{The ethical assessments of two zootouristic practices in Mexico: questions about animal geography}

\begin{abstract}
In Mexico, the donkey (Equus africanus asinus), has been commercialized as a working animal and tourist resource, and its image has become part of the heritage and collective identity in at least two locations. On the one hand, the zebra-donkey has been painted with stripes to simulate an African zebra and is tied to a cart so that tourists who visit Tijuana are photographed dressed in a Mexican poncho and with a traditional hat to take a souvenir from this city border. At the Donkey Fair in Otumba, donkeys are the protagonists of different shows and sports that reinforce the relationship between humans and animals. This article, elaborated from qualitative methods and techniques, reveals the construction of donkeys as rootouristic resources and the ethical implications of this social construction given the commodification of these non-human animals.
\end{abstract}

Keywords: animal tourism; non-human animals; heritage; animal ethics; animal geography.

\section{(c) $(1) \odot$}

DOI: https://doi.org/10.26512/patryter.v3i5.27014

Como citar este artigo: Quintero-Venegas, G. J.; Rosales-Estrada, P. T. (2020). Las valoraciones éticas de dos prácticas zooturísticas em México: cuestiones sobre geografia de los animales. PatryTer - Revista Latinoamericana e Caribenha de Geografia e Humanidades, 3 (5), 30-41. DOI: https://doi.org/10.26512/patryter.v3i5.27014

Recebido: 02 de setembro de 2019. Aceite: 05 de dezembro de 2019. Publicado: 01 de março de 2020.

${ }^{1}$ Investigador posdoctoral del Programa de Becas Posdoctorales en la UNAM. ${ }^{\mathrm{i}}$ ORCID: https://orcid.org/00000001-6472-3433. E-mail: jafquven@gmail.com.

${ }^{2}$ Becaria del Instituto de Geografía en la UNAM. ORCID: https://orcid.org/0000-0002-0149-3914. E-mail: perlauri15@,outlook.es. 


\section{Introducción}

México es un país en donde se han desarrollado algunas prácticas turísticas cuya finalidad es vivir experiencias con animales no humanos. Dentro de la diversidad de estas prácticas, a las que Fennell (2012) llama zooturismo, hay dos en concreto en donde el burro (Equus africanus asinus) ha sido mercantilizado y cosificado por la búsqueda de la "autenticidad" por los turistas: la recreación con el burro-cebra en Tijuana, Baja California, y la Feria del Burro en Otumba, Estado de México. Ambas, consideradas como patrimonio por la población local, han consolidado la imagen del burro como sinónimo de identidad comunitaria. su presencia y quienes condenan su uso por ser maltrato animal.

La Feria del Burro de Otumba, en el Estado de México, es una celebración anual que data de 1965 (Carranza, 1999). Se realiza durante abril y mayo y consiste en una serie de espectáculos en donde los burros son el atractivo principal: polo sobre burro, carreras de burros, y el desfile de burros disfrazados. La población local de Otumba percibe a la Feria como parte de su patrimonio cultural y, tanto aquí como en Tijuana, las actividades turístico-recreativas con los animales no humanos se legitiman por la remuneración económica que generan, por la identidad y cohesión social de ciertas comunidades, y por la tradición (Figura 1).

Figura 1 - Ubicación de Tijuana y Otumba en México

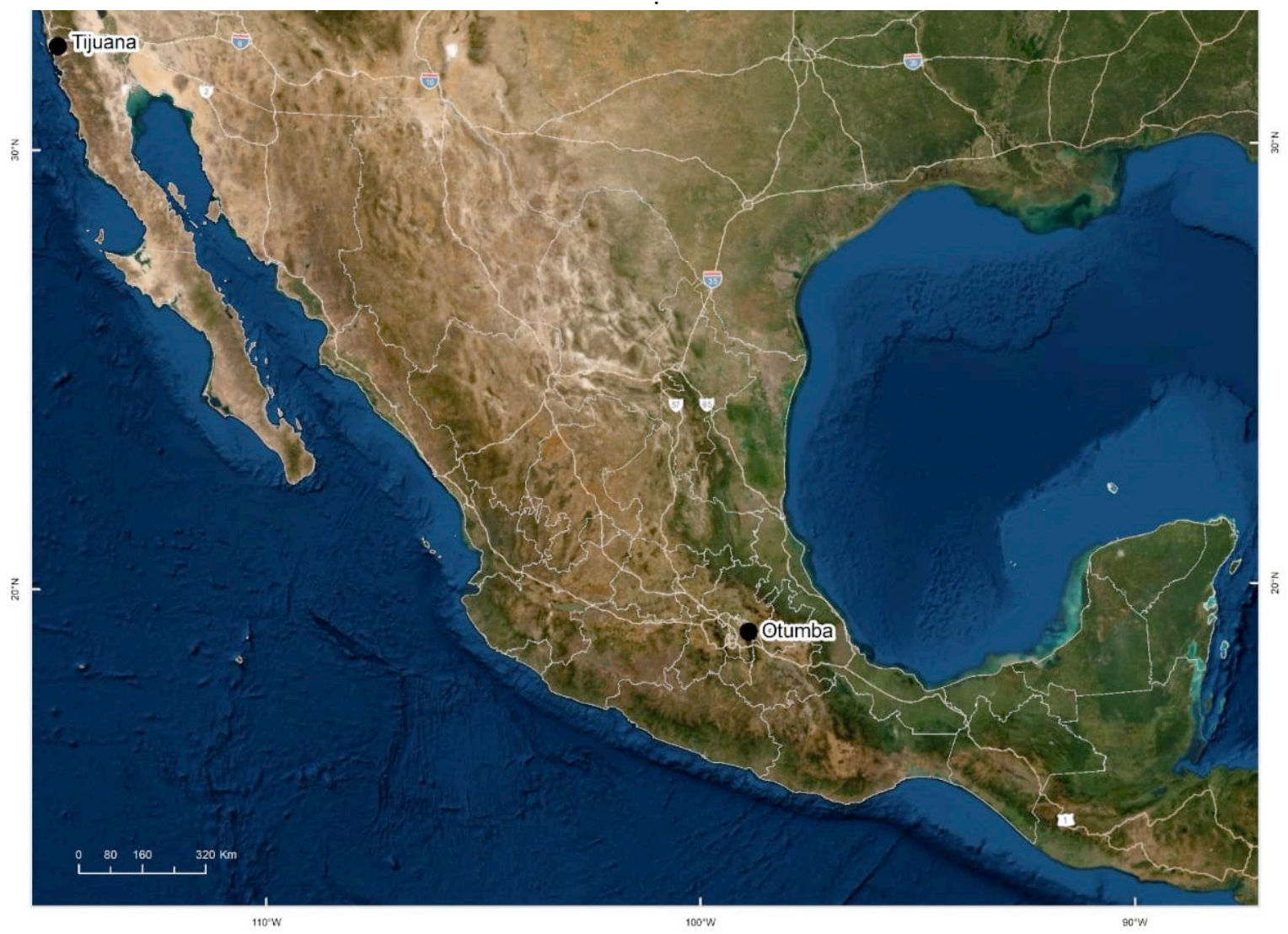

Fuente: elaboración propia.

El burro-cebra, un burro pintado con rayas para simular una cebra africana, ha sido un ícono turístico en Tijuana -ciudad en la frontera norte de México- desde hace más de cien años, y patrimonio estatal desde 2014. Este animal no humano trabaja doce horas diarias de pie amarrado a una carreta para que los viajeros se fotografíen vestidos con atuendos tradicionales mexicanos. $\mathrm{Su}$ denominación como patrimonio ha polarizado a la población local en dos bandos: quienes defienden
El objetivo principal de este trabajo es revelar porque estos dos ejemplos de prácticas turísticas en donde los burros son los protagonistas, son antiéticas. En ambos casos, los animales no humanos han sido cosificados y no se les respeta su interés primario a no sufrir y son sometidos a arduas jornadas de trabajo no remuneradas. El texto fue elaborado a partir de los postulados de la Geografía de los Animales, una subdisciplina transversal a diferentes especialidades 
constituyentes de la geografía humana y que reflexiona sobre la espacialidad en las interacciones entre animales humanos y no humanos desde una postura ética posthumanista.

\section{Metodología}

Esta investigación se elaboró a partir de la base teórico-metodológica de la Geografía de los Animales que propone utilizar la triangulación de diferentes técnicas cualitativas (Decrop, 1999; Buller, 2015) para reflexionar sobre la relación del ser humano con los otros animales (Urbanik, 2012; López y Quintero, 2020). En primer lugar, se hizo una revisión bibliográfica, hemerográfica y virtual exhaustiva de los documentos escritos sobre la dinámica turística del burro-cebra en Tijuana; sobre la historia y actualidad de la Feria del Burro en Otumba; y sobre los postulados más recientes en torno a la zooética.

Después, la hermenéutica diatópica se utilizó para discernir sobre los planteamientos éticos en los discursos relativos al uso de animales de trabajo en contextos turísticos. Esta técnica consiste en interpretar textos a partir de la fenomenología que, como sostiene Ángel (2011, p. 19), "el investigador explicita [con] las perspectivas filosóficas de su aproximación, orientadas a percibir la manera como la gente [y los textos] interpreta[n] un fenómeno". La validez de esta técnica radica en ser "un procedimiento de traducción entre saberes pertenecientes a sistemas culturales diversos, [y] un modelo para el diálogo intercultural" (Vergalito 2009, p. 20).

Para el análisis del discurso virtual de las opiniones de los turistas vertidas se usó la netnografía a partir de la revisión de diferentes sitios web que referían a Tijuana y a Otumba como destino turístico: Facebook, Trip Advisor y Wikitravel. Esta técnica, preferida sobre las entrevistas y las encuestas permitió conocer tanto las recomendaciones de viaje que se hacen en ambas localidades, como las opiniones de los turistas con respecto a las prácticas con los burros (Tierney, 2000). La validez de esta práctica radica, de acuerdo con Mkono (2011), en que es más probable obtener respuestas honestas y sinceras en el entorno virtual porque los participantes se unen a la blogosfera por su propia voluntad y porque pueden asumir identidades seudónimas o anónimas.

Adicionalmente, se recurrió a la observación no participante y participante in situ en Otumba para reconocer las prácticas (zOo)turísticas que se contraponen con el bienestar animal (Angrosino, 2012). Allí, en 2018, se realizaron doce entrevistas semidirigidas a los turistas para conocer las razones por las que visitaban la Feria del Burro. Adicionalmente, el fundador del santuario "Burrolandia", Germán Flores, concedió una entrevista que sirvió para contrastar su perspectiva como propietario sobre la Feria del Burro con la de los visitantes.

\section{Geografía de los Animales, ética y prácticas turísticas}

Las relaciones entre animales humanos y animales no humanos se han estudiado desde diferentes disciplinas académicas desde el paradigma antropocéntrico que legitima el uso de los animales no humanos para satisfacer necesidades humanas (Horta, 2017). Esta forma de abordaje de nuestras relaciones con los otros animales suele pasar por alto el trato ético de las prácticas donde los animales no humanos son mercantilizados e ignora las responsabilidades que se tiene hacia ellos. De hecho, niega su sintiencia, les priva de su bienestar, normaliza su uso como fuerza laboral e, incluso, permite que se les arrebaten sus derechos territoriales (Horta, 2017; Tavera, 2016).

Con la publicación del libro "Animal Geographies" en el mundo anglosajón, editado por Jody Emel y Jennifer Wolch en 1998, se empezó a desarrollar el nuevo campo de conocimiento geográfico conocido como la Geografía de los Animales (Urbanik, 2012; Quintero y López, 2020). Ésta es una subdisciplina transversal que reflexiona sobre la espacialidad en las interacciones entre animales humanos y no humanos (Quintero y López, 2020). Su principal objeto de estudio son "las complejas relaciones humano-animal con el espacio, lugar, ubicación, entorno y paisaje", y analizar "dónde, cuándo, por qué y cómo los animales no humanos se cruzan con las sociedades humanas" (Urbanik, 2012). Además, incorpora el análisis de la validez ética de los espacios en donde se llevan a cabo dichas interacciones desde un paradigma posthumanista (Urbanik, 2012; Quintero y López, 2020).

Bajo el humanismo, la Geografía ha observado a los animales no humanos desde una posición antropocéntrica que los considera como "recursos naturales" (Urbanik, 2012; Quintero y López, 2020). Desde el posthumanismo, se plantea que el ser humano no es esencialmente superior a los otros animales (Weil, 2012) al abogar por praxis antiespecistas (Horta, 2017) y aspirar a relaciones de interacción desde una nueva ética que valore la capacidad de sintiencia y autoconsciencia del reino animal en su conjunto. La Geografía de los 
Animales no solo toma en cuenta a los espacios vividos de los propios animales y las interacciones con otros seres vivos -incluidos los seres humanos- (Lynn, 1998; Urbanik, 2012), sino que niega las diversas etiquetas teleológicas (o de finalidad) que les hemos atribuido arbitrariamente a los animales. Así, la posición posthumanista en Geografía reprueba el papel que los animales no humanos han jugado en la construcción de ambientes turísticos porque son poco éticas y porque se han legitimado a partir de la dominación, la violencia y el desdén hacia la otredad (Quintero y López, 2018).

La Geografía de los Animales desvela cómo es que la calidad de vida de los humanos se basa en el uso y explotación de los animales no humanos, pues es la sociedad humana la que ha creado categorías antropocéntricas que justifican su teleología o finalidad última (Flores y Terán, 2017); de esta manera, Urbanik (2012) alude a tres grandes grupos de animales no humanos: 1. Los de trabajo que a su vez los subdivide entre los etiquetados para la educación (laboratorios, zoológicos), los de servicios (tiro y carga, pastoreo, caza, de apoyo en el cumplimiento de la ley, terapias, compañía) y los de entretenimiento (grabaciones y filmaciones, circos, peleas, carreras y rodeos). 2. Los de granja, reconocidos como aquellos que en algún momento han sido extraídos de su entorno silvestre para su domesticación y obtener de ellos no sólo alimentos si no muchos otros productos, como aquellos usados en la industria textil y farmacéutica. 3. Los silvestres, aquellos que permanecen en entornos relativamente distanciados de la ecúmene, pero que no están exentos de su expoliación a través de la caza o la pesca.

Con esto, Urbanik (2012) deja ver que las relaciones entre animales humanos y no humanos son espacialmente ubicuas, con límites económicos, políticos, sociales, culturales, legales y ecosistémicos, en función de las necesidades humanas, de modo que la nueva geografía de los animales también evidencia las relaciones jerárquicas inequitativas, para así revelarlas, pues "ya no hay una clara línea divisoria entre los humanos (sujetos) razonables, emocionales, agenciales y conscientes por un lado y los 'tontos' animales (objetos) pasivos y mecánicos por el otro" (Collard y Gillespie, 2015, p. 8; traducción propia).

Finalmente, Urbanik (2012) dice que las interacciones entre animales humanos $y$ no humanos están definidas por geometrías del poder y que sus asimetrías -básicamente de sometimiento humano- están estrechamente asociadas con los espacios en que se llevan a cabo y el tipo de interacciones. Desde esta posición, abordar el problema del espacio no sólo implica dar cuenta de una dimensión presente en toda actividad humana, sino que la comprensión de la espacialidad es una manera de aproximarse a los procesos a través de los cuales se constituye una sociedad, sus patrones culturales y su identidad (Massey, 1993; Velázquez, 2013).

\section{La adopción del burro-cebra como recreación y patrimonio tijuanense}

Tijuana, con 1.6 millones de habitantes, es la quinta ciudad más poblada de México y la mayor urbe de Baja California (INEGI, 2015a). Como ciudad global (Bringas, 1991), forma parte de la aglomeración transfronteriza internacional San Diego-Tijuana y su crecimiento se debe al asentamiento de la industria maquiladora en el decenio de los setenta (Walker, 2011). Asimismo, su situación fronteriza y de poca articulación geográfica hacia el centro del país ha hecho que la organización de su actividad turística dependa, casi en su totalidad, de los visitantes estadounidenses (Carmona y Correa, 2008).

La historia del burro-cebra se remonta a finales del siglo XIX, cuando la imagen que se tenía de México era similar a aquélla del salvaje oeste estadounidense. Cuando se cruzaba la frontera desde California hacia México, al viajero se le ofrecía una fotografía que capturara su experiencia turística de forma estereotipada: montado en un burro y vistiendo el atuendo tradicional mexicano. Sin embargo, como las imágenes de ese momento no eran tan nítidas, el burro se perdía entre las tonalidades del blanco y negro (Cháidez, 2012) (Figura 2).

Figura 2 - El burro de Tijuana en blanco y negro

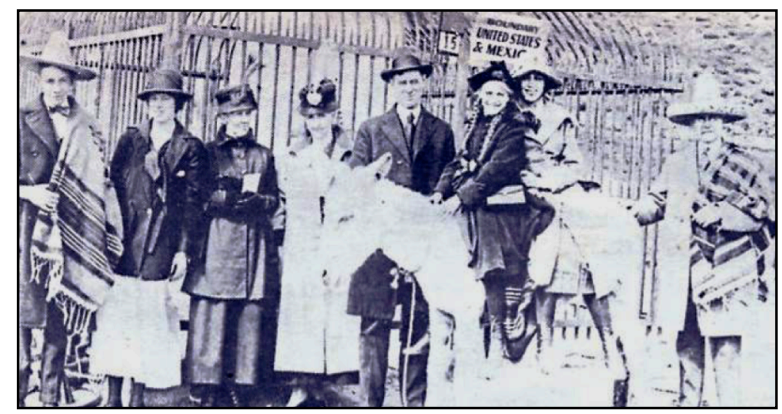

Fuente: El Debate, 2017.

A inicios del XX, Tijuana empezó a recibir grandes contingentes de visitantes porque con la declaración de la Ley Seca en California, en 1915, y la de Texas, en 1918, varios negocios vinculados con la venta de alcohol se desplazaron hacia la frontera norte de México (Carmona, 2003). Como respuesta, las autoridades estadunidenses 
decidieron limitar los flujos de personas y acotar los tiempos de cruces fronterizos para "no poner en riesgo (ni) la moral (ni la) condición social de la población de San Diego" (Carmona, 2003, p. 47). Esto impactó negativamente en la derrama económica local aunque favoreció al sector hotelero por la necesidad de los estadunidenses de pernoctar en el territorio mexicano (Bringas, 1991; Ceballos, 1991).

Para que Tijuana fuera un espacio más atractivo hacia los extranjeros, la oferta recreativa se diversificó a partir de juegos de azar y de espectáculos basados en el uso de animales no humanos (Carmona, 2003). El enclave de Agua Caliente, un casino ubicado a $3 \mathrm{~km}$ del centro de la ciudad que albergó al galgódromo y al hipódromo, se edificó en 1927 con mano de obra local y migrante (Cháidez, 2012). Con la llegada masiva de turistas estadunidenses a Tijuana que buscaban un suvenir de la ciudad, el burro-cebra se empezó a consolidar como un elemento de identidad:

"...Sólo habia un hombre que se diferenciaba de los demás por lo particular de su trabajo. Se trataba de Manuel 'El Muletero' [quien,] [a]l ver la llegada de camiones llenos de turistas y lijosos automóviles que pasaban bajo la estructura de la Antigua Torre [de] Agua Caliente para llegar al complejo, [...] supo que abi se encontraba una mina de oro. [...] [Estaba] probibido tomar gráficas en el interior del casino $y$, por consecuencia, eso obligaba al turista a pedirle a Manolo un recuerdo del Casino. Sentados a la salida del hotel o el almacén de novedades, los visitantes posaban muy orondos con el sombrero mexicano, mientras Manolo - con una cotorra en el hombro- realizaba su trabajo gráfico. Eran tiempos aquellos donde un burro era cubierto con una cobija de colores y adornos festivos, donde se sentaba una bailarina, y se realizaba un espectáculo llamado Fiesta mexicana'...” (Cháidez, 2012, s/p)

En 1938 se prohibieron los juegos de azar en territorio mexicano (Andrade, Moreno y Quiñones, 2015). Cuando el casino de Agua Caliente cerró definitivamente, el hábito de tomarse una foto encima de los burros ya estaba tan arraigado que las personas dedicadas a ello se habían multiplicado. Incluso, las carretas de los burreros se habían trasladado a la Avenida Revolución -la primera vialidad pavimentada de la ciudad-porque estaba en proceso de convertirse en la médula espinal de la movilidad turística de los visitantes que cruzarían a diario la línea fronteriza desde San Diego, California (Carmona, op. cit.).

De acuerdo con Morales (2016) y con Vincent (2018), la foto más antigua del burro-cebra data de 1939 cuando el burro ya estaba ubicado sobre la Avenida Revolución. Cháidez (op. cit), explica que la idea de pintar rayas a los burros con tinte para el cabello resultó de la experiencia de un burrero que observó a las cebras africanas cuando visitó el zoológico de San Diego, y que concluyó que las rayas ayudarían a identificar el contraste en las fotografías en blanco y negro (Figura 3).

Figura 3 - Un niño posando con el burro-cebra de Tijuana en 1949

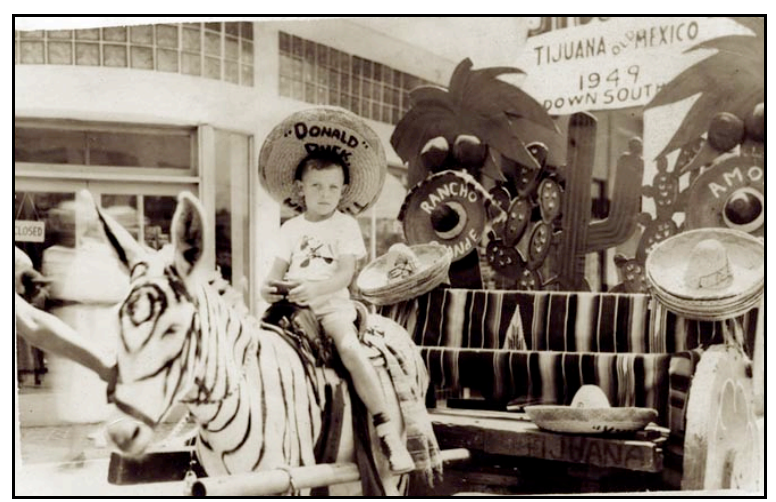

Fuente: Vincent, 2018.

Durante la Segunda Guerra Mundial, la llegada de soldados y marinos estadunidenses al puerto militar de San Diego y a la franja fronteriza aumentó la demanda de espacios recreativos en Tijuana (Carmona, op, cit). Para atraer a más turistas, la decoración del burro se cambió por alusiones a los imaginarios que se tenían de México como nopaleras y paisajes desérticos (Observatorio Turístico de Baja California, 2015). Para 1945, la popularidad de los burros-cebras era tal que sobre la Avenida Revolución había hasta veinticinco de estos animales no humanos. Además, se formó un sindicato de burreros para evitar que otras personas se dedicaran a dicha actividad y que sólo los miembros adscritos pudieran trabajar como fotógrafos oficiales (Vincent, 2018).

Para 1950, Tijuana empezó a adquirir importancia como destino turístico nacional porque se construyeron las carreteras que la vincularon con otras ciudades del interior del país, y porque se abrieron las rutas aéreas comerciales México-Tijuana y Acapulco-Tijuana (Carmona, 2003). Al burro-cebra se le agregaron elementos culturales híbridos como sillas de montar y sombreros de palma con leyendas como "Just Married", "Amigo", "Tijuana" o "The Boss" (Vincent, 2018). Las nuevas decoraciones pretendían hacerlo más atractivo para los turistas y reproducir un folclorismo kitsch idealizado (Palaversich, 2002). 
En 1964, Estados Unidos finaliza el programa "Braceros" que otorgaba concesiones laborales agrarias a mexicanos desde la Segunda Guerra Mundial. Con el retorno de los migrantes, la población de Tijuana creció y un porcentaje significativo se empleó como mano de obra en maquiladoras de origen extranjero (Carrillo y Hualde, 2000). Sin embargo, aquéllos que no lograron colocarse en un trabajo formal empezaron a auto emplearse sobre la Avenida Revolución a partir del comercio informal (como vendedores de artesanías, productos chinos...) o, incluso, como burreros apócrifos (Íbid).

La situación de irregularidad de varios burreros se mantuvo hasta el último decenio del siglo pasado por todas las facilidades de ingreso que recibieron los compatriotas mexicanos con la implementación del programa "Paisano" y por la intensa promoción para transformar a Tijuana en un espacio de turismo internacional (Ruiz, Martínez y Verján, 2015). Al mismo tiempo, el Programa Nacional de Turismo propuso ampliar la oferta de actividades e impulsar el turismo carretero y el cinegético. Se mejoró la imagen de las ciudades fronterizas para incrementar la estancia y el gasto de los visitantes y, con ello, exhibir burroscebra famélicos o en mal estado no tuvo cabida (Carmona, 2003).

Tijuana, al ser un lugar de tránsito binacional, posee una dinámica turística distinta con respecto a otras ciudades mexicanas. En términos generales, el turista extranjero busca en la ciudad actividades que no se relacionan directamente con el medio natural, sino con el alcohol, las drogas, el juego, los servicios médicos y la prostitución (Bringas, 1991). Este contexto espacial tan peculiar actual volvió al burro-cebra un complemento de la oferta turística al que, además, se le ha considerado como patrimonio en los últimos años.

En 2013 se propuso que el burro-cebra fuera considerado Patrimonio Cultural de la Ciudad por su importancia en la construcción histórica de la identidad de Tijuana (Notimex, 2014; Martínez y Contreras, 2017). El 8 de agosto de 2014 se le designa como Patrimonio Cultural del Estado de Baja California (Observatorio Turístico de Baja California, 2015) de forma muy controvertida. Por un lado, estaban quienes aprobaron la decisión con base en su valor cultural, y otros que rechazaron el nombramiento a partir de cuestiones éticas hacia los animales no humanos. Tras varias pugnas entre ambos bandos, en 2017 abogados a favor de los derechos de los animales consiguieron un amparo para que el burro-cebra dejara de ser patrimonio y, actualmente, se está buscando que vuelva a ser considerado como tal (Newsweek México, 2017).

\section{El burro-cebra: un elemento no ético del patrimonio}

El patrimonio remite a la huella material -política, económica y cultural- de los grupos dominantes y se ha manifestado como la impronta de quienes ejercen el poder (González y Hiernaux, 2015). Se ha asumido como un instrumento de identidad y cohesión social (Troitiño, 1998) y como la expresión de valores artísticos, filosóficos y morales, que conforman la tradición. Sin embargo, su función en relación con el resto de esferas que componen la vida civil ha cambiado en los últimos años porque prevalece su valor económico sobre el cultural y el político.

La declaración patrimonial del burro-cebra fue la primera vez que se al animal se le otorgaba un reconocimiento de tal magnitud y eso lo consolidó como el ícono de la frontera y el atractivo turístico más famoso de la Avenida Revolución. Sin embargo, la declaración fue severamente rechazada por aquellos tijuanenses que perciben su uso como maltrato y abuso:

\begin{abstract}
Que los quiten, ya sacaron mucho provecho de ellos y los pobres burros todos cansados de estar pardos bajo el rayo del sol, eso es una crueldad, mejor que se ponga el dueño del burrito y se pinte como cebra y lo monten los turistas a ver si no se va a enfadar de estar para todo el día sin comer ni tomar agua. Gente de mente retrógrada. (Notimex, 2015).
\end{abstract}

¿Desde cuándo se considera trabajo maltratar animales? 'Los animales no tienen la culpa de que los dueños no hayan sido responsables de planificar su vida! (Notimex, 2015).

En 2015, grupos a favor de los derechos de los animales solicitaron un amparo para retirar la declaración del patrimonio del burro-cebra no sólo porque permanecen de diez a doce horas postrados bajo el sol en condiciones que atentan contra su bienestar, sino porque legitima el uso de los burros como animales de trabajo, porque se les percibe como simples recursos que sirven para el deleite de los turistas, y porque se contrapone con la ley de maltrato animal de la ciudad (Merlo, 2016). La alternativa propuesta por este grupo consiste en usar burros de fibra de vidrio en vez de animales vivos, para que la tradición continúe sin ninguna situación de maltrato (Notimex, 2015).

\section{La Feria del Burro y la construcción de la identidad en Otumba}

Otumba, municipio rural al noreste del Estado de México y de poco más de 35,000 habitantes (INEGI, 2015b), presenta un elevado 
índice marginación con el 56.5\% de su población bajo el umbral de pobreza y el $19.7 \%$ en situación de rezago educativo (CONEVAL, 2010). Al igual que en la mayoría de las localidades pequeñas del centro del país, el sustento económico radica en la agricultura del nopal y en la ganadería de traspatio para autoconsumo. Sin embargo, desde 1965 allí se celebra la "Feria del Burro" como alternativa de crecimiento económico. Su importancia es tal que hoy, la festividad significa la mayor derrama económica de la localidad.

La identidad de Otumba se ha construido a partir de la figura del burro. Un ejemplo de ello es la presencia de una estatua a la entrada del municipio que enaltece la figura del tlachiquero, el trabajador del campo que sustrae el aguamiel de los magueyes -la materia prima del pulque- y visibiliza el papel del burro como animal de trabajo, carga y transporte en dicho proceso productivo: "El burro y el tlachiquero". Este monumento también conmemora el quincuagenario de la Feria del Burro y enaltece el sentimiento de identidad cultural al interior del municipio (Ramírez, 2015).

En Otumba también existe Burrolandia, un santuario animal fundado en 2006 en donde se han acogido a varios burros con el fin de evitar su extinción y el de educar a la población asistente sobre la especie (Miranda, 2018). De acuerdo la entrevista que se le hizo al fundador, Germán Flores, este espacio es una fuente alternativa de crecimiento para la comunidad en donde se aprovechan los recursos turísticos locales (sic.), y donde se refuerza la identidad histórica del municipio y el fuerte vínculo con el burro:

"El burro es identidad. [...] La arriería comenzó a llevarse a cabo en nuestro país después de la conquista en 1521. Se conoce ya la rueda, que se conocía bace cinco mil años en Europa y empiezan a llegar también junto con la rueda, los carruajes y las bestias de carga. Esas bestias de carga, caballos, burros y mulas. [...] Otumba queda como punto intermedio entre Veracruzy la Ciudad de México [...] se hacen mesones donde tenian que descansar, y esos mesones, pues, empiezan a tener éxito [y] a tener mucha afluencia, por lo que lleva también a que se haga un mercado regional de bestias de carga, entre ellos, caballos, mulas y burros... Es abi donde nace la frase, después de que ese mercado se hace famoso. Si alguien quería conseguir un burro se decía: para burros, los de Otumba'. Nace abi la identidad de Otumba."

La primera Feria del Burro se celebró el 1 de mayo de 1965 para coincidir con la conmemoración del día del trabajo y festejar "al animal más trabajador" (Miranda, 2018). Sin embargo, es hasta el año 1972 que la feria adquiere mayor popularidad a nivel nacional porque la actriz mexicana María Elena Velasco, mejor conocida como la India María, graba la película "Tonta, tonta, pero no tanto" (Pata de Perro, 2019). En el filme, Otumba es el escenario de la localidad ficticia de San José de los Burros y el hogar del burro Filemón, compañero de la protagonista (Rotten Tomatoes, s/f). Desde entonces, aproximadamente cien mil personas concurren anualmente a la feria.

Actualmente, sólo dos familias originarias de Otumba participan en la feria porque el Gobierno del Estado de México ha mercantilizado y elitizado el evento. Desde el año 2018, el espectáculo con burros dejó de realizarse en la explanada central del pueblo para trasladarse al "burródromo", un espacio abierto y privado acondicionado con un escenario y gradas alrededor en donde se cobra la entrada en 40 pesos. El costo de ingreso al evento es significativo si se considera que más de la mitad de la población vive bajo una situación de pobreza. Así, son los mismos funcionarios quienes participan, rentan o piden prestados a los burros y los premios generalmente los gana el ayuntamiento.

\section{E1 espectáculo con burros en la feria de Otumba como elemento recreativo turístico}

La Feria del Burro se realiza anualmente durante los últimos días de abril y concluye el 1 de mayo. Entre sus principales atracciones están la noche de fogata, la carrera de burros, el concurso de burros disfrazados y el campeonato de polo sobre burro. Además, se ofrece venta de artesanías, espectáculos de danza folclórica, shows de comedia y comercio de productos gastronómicos elaborados, en su mayoría, con ingredientes de origen animal: barbacoa, mixiotes de carnero, y tacos de gusanos de maguey y escamoles (Donde Hay Feria, 2019).

De entre todos los espectáculos en la feria, el polo sobre el burro es uno donde la explotación hacia los animales no humanos es más visible. Dos equipos de cinco integrantes montan a los burros y cada miembro trae consigo una escoba para empujar una pelota de plástico hacia la portería del equipo contrario. Para tratar de anotar y dirigir a los burros hacia donde los jinetes quieren, se les jala y se les golpea. El sobrepeso de los jinetes y el ruido que hace la audiencia por el éxtasis de la competencia se suman a las molestias que padecen los burros en esta competencia cuya finalidad es recibir un premio en efectivo. 
Las carreras sobre burros se dividen en tres etapas alternadas entre el desfile, la presentación de algunos grupos musicales, y la animación por parte de patiños y botargas. Consiste en montar a los burros y golpearlos en sus vientres y grupas con los pies y con fuetes para que corran. La carrera es una actividad plenamente masculina y no hay edad para participar. Además, es el espectáculo más disfrutado y esperado por el público:

\footnotetext{
"No pues, la verdad vine porque quería ver qué es la feria del burro. [...] Cada año sale que la feria del burro... y no habia venido! Hoy vine porque me interesaba ver qué era en realidad la carrera, bueno la feria del burro. Asi ya no me lo cuentan. Ya lo vi..." (Pedro, 01 de mayo del 2019).

"Bueno, no veíamos muy bien... pero imuy bonito [...] eso del desfile! Los disfraces de los burros muy bonitos; el que premiaron estuvo bien y las carreras también. El niño muy motivado, sirve que se motiva más gente de aquí." (María, 01 de mayo del 2019).
}

El desfile de burros se celebra antes de la carrera final. Los participantes buscan ganar el premio al disfraz más original y el certamen se decide a través de los gritos y aplausos de los espectadores. Los dueños diseñan los atuendos que visten los burros y, aunque el tema es libre, abundan los de alusiones políticas y los que simulan personajes de caricaturas. Muchas veces, los disfraces significan incomodidad para los burros porque se exceden en peso, porque la ropa y el calzado les estorban para caminar y porque los pintan con maquillaje que puede ser tóxico (Figura 4).

Figura 4 - El Burro Apache, ganador del desfile del 1 de mayo de 2018

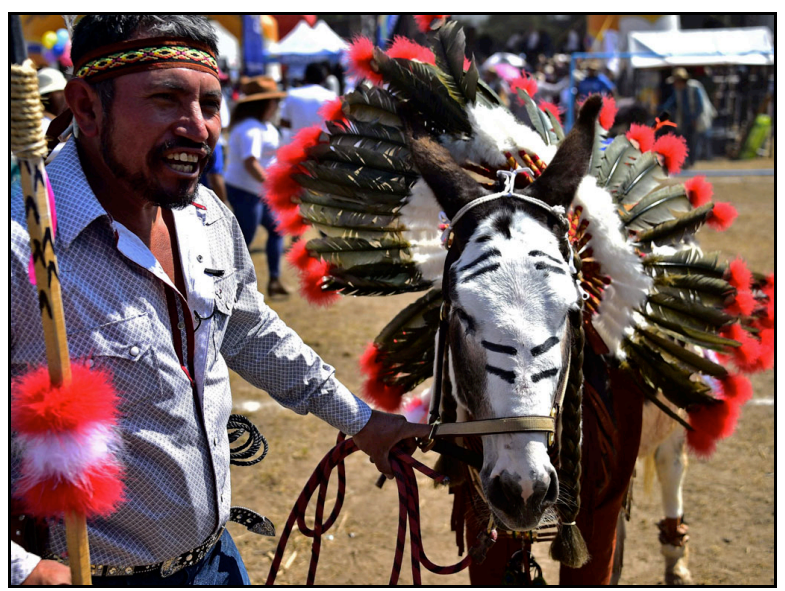

Fuente: Periódico Correo, 2018.

\section{Invisibilización del especismo durante la Feria del Burro}

Los espectáculos realizados durante la Feria del Burro normalizan el uso de los animales no humanos como recursos, legitiman su cosificación, e invisibilizan el especismo del proceso económico. En La Feria, la idea de identidad y de tradición prevalece en los pobladores por encima del bienestar animal ya que se percibe como una alternativa de desarrollo local. Además, para los visitantes, es un elemento patrimonial inamovible que le otorga a Otumba un carácter de unicidad y originalidad.

Sin embargo, desde una postura ética posthumanista, el argumento cultural para mantenerla es muy endeble. Existen prácticas culturales que han desaparecido y que han involucrado maltrato animal, como las antiguas peleas de osos en Inglaterra o como el Kots Kaal Pato en Yucatán. En ninguno de los dos casos su extinción repercutió en la pérdida de identidad local. Además, en un mundo tremendamente globalizado, es muy dudoso que Otumba deje de ser Otumba si se eliminara la utilización de los burros en la feria (Ortiz, 2018).

Por otro lado, aún existe un sesgo teleológico hacia los burros como animales de trabajo y recreación en Otumba que legitima su maltrato en prácticas como la Feria del Burro:

'No, pues, a eso vienen destinados los animalitos; a
participar también. Si se da cuenta no los maltratan
tanto porque los animalitos ya están impuestos a las
carreras." (Pedro, 01 de mayo del 2019).
'Pues yo pienso que no jeh?; yo pienso que no. O sea
[hay] maltrato porque [...] le pegan al animal pa'
que corra ino? Pero, pues, yo digo que para el
animalito no es un maltrato. Yo pienso que es normal
¿no? Para que tenga... o sea pueda correr el animal.
También lo hagan correr, más que nada."
(Margarita, 01 de mayo del 2019).

La Feria del Burro es un espectáculo que valora a los burros a partir de su valor extrínseco, es decir que son percibidos como recursos semovientes que generan derrama económica y que son necesarios para mantener la festividad. Esta es una característica muy común en el patrimonio puesto que valorarlos de forma intrínseca y aceptar que sus intereses no están automáticamente subordinados a los intereses humanos conllevaría a plantearnos la validez de la feria (Horta, 2017). El discurso para realizar la feria se ha centrado en la conservación de la especie, prevenir su extinción, y enaltecer al burro como un ser que le ha ayudado al ser humano a realizar trabajos. Sin embargo, la 
realidad es que a los burros se les explota, se les mercantiliza y lejos están de obtener un beneficio real.

\section{La situación de explotación y maltrato animal en el uso turístico de los burros}

Las actividades económicas en donde los animales no humanos son vistos como el sustento económico de las poblaciones locales generan esquizofrenia moral en algunos humanos (Francione y Garner, 2010). A ciertos animales se les ha considerado como objetos aunque al mismo tiempo se sea consciente de que en realidad no lo son porque sienten y tienen intereses. Cuando se visibiliza la explotación hacia los animales no humanos, ésta se lamenta y se pone en tela de juicio la cosificación de los animales por asociarse con prácticas en donde hay "maltrato" animal. Sin embargo, es necesario remarcar que el concepto de "maltrato" es erróneo porque existe sólo en oposición al "buen trato" dentro de una relación que ha sido consentida libremente por ambas partes (Rebollo, Polderman y Moya, 2010). Ni en Tijuana ni en Otumba los burros tienen opción de decidir.

Históricamente se ha asumido que usar y esclavizar animales no humanos para satisfacer necesidades humanas es una acción aceptable, y sólo se considera maltrato cuando se les daña más allá de lo necesario (Arluke, 2002). A partir del significado de "lo Moderno" y "lo civilizado", se asevera que criar, consumir y comerciar con animales es un acto positivo (Elias, 1994) siempre y cuando no sufran excesivamente, no estén hacinados en espacios demasiado pequeños, no estén de pie ni a la intemperie, y no sean obligados a cumplir jornadas laborales extenuantes.

Visibilizar y condenar el maltrato animal en las prácticas turísticas ha hecho que los explotadores encuentren alternativas para disminuirlo, sin eliminarlo, a partir de prácticas bienestaristas. A lo más que hemos podido llegar en el contexto mexicano es a que se promulguen normas que dicten la forma "correcta" de explotarles, como la propuesta de Ley de Bienestar Animal que, más que percibir a los animales no humanos como seres sintientes, los ve como bienes consumibles cuyo uso se debe regular, sin resolver el problema de la explotación de raíz (Horta, 2017):

Artículo 60. Las legislaturas de las entidades federativas, en el ámbito de sus respectivas competencias, emitirán las

\section{disposiciones correspondientes a efecto de regular:}

\section{La utilización de animales en deportes y espectáculos públicos. En aquellas entidades donde se permitan espectáculos que pongan en riesgo la salud, integridad y vida de animales, se deberá garantizar el bienestar de estos en caso de que sobrevivan, o bien aplicarles la eutanasia. (Cámara de Diputados, 2019).}

Al ampliar el espectro moral hacia los animales no humanos (Fennell, 2012) se asume que es éticamente incorrecto utilizarles sin su consentimiento. Así, prácticas como la del burrocebra o como la carrera de los burros de Otumba no sólo representan maltrato sino que debieran ser erradicadas. El uso de los burros en Tijuana y en Otumba implica explotación porque se realiza directamente contra su voluntad y, a menudo, se atenta contra sus intereses básicos de continuar existiendo y de evitar el daño y el sufrimiento. Además, se anteponen con lo establecido en la Declaración de la Conciencia de Cambridge, firmada en 2012, en que se asevera que los animales son sujetos que tienen voluntad, intenciones, deseos e intereses propios, y que experimentan su vida a través de sensaciones, emociones, deseos (Horta, 2017).

\section{Discusión y reflexiones finales}

Al ampliar el espectro moral más allá del antropocentrismo, se concluye que el uso de los burros como mercancía, como recurso turístico o como elemento patrimonial es una consecuencia más de una deliberada desconsideración moral resultante de la mentalidad supremacista, alimentada por un sistema de creencias, intereses, valores y costumbres que resultan del especismo. Urge que éste sea reconocido como una forma de discriminación por los aparatos legales para que se ponga atención en la injusticia y la explotación y que se regulen las prácticas turísticas y recreativas que tienen como base la interacción con los animales no humanos.

Cosificar a un ser sintiente es sinónimo de volverlo un recurso disponible cuyo uso no es consensuado. Aunque el burro-cebra haya sido nombrado patrimonio y los burros de Otumba sean vistos como sostén económico, esas etiquetas no le restan importancia a la explotación que padecen estos animales no humanos solo brindarle un servicio hedonista a los turistas. Si se amplía la consideración moral de lo válido y lo no válido en prácticas laborales y turísticas hacia los animales, 
ésta es una práctica no ética que atenta contra los derechos básicos de los burros y que debería transformarse o abolirse porque: 1 . No es ético que un ser sintiente sea cosificado para mercantilizarle como un producto turístico. 2. La denominación de "patrimonio" hacia un animal de trabajo no normaliza y justifica su uso para obtener una ganancia económica. 3. No se debe construir ni el soporte económico ni la identidad colectiva a partir del abuso y el maltrato hacia los demás animales.

Además, las prácticas turísticas con los burros refuerzan las relaciones de poder entre especies. Los seres humanos coaccionan a los otros animales para que los últimos hagan algo a cambio de darles comida, cobijo o de evitarles un castigo. Los animales no humanos tienen noción de que están sometidos y actúan por miedo, motivados por el dolor que les causan los homo sapiens; consienten su esclavitud porque acceden a trabajar para evitar represalias, porque están coaccionados por sus explotadores, y porque no pueden optar a otra cosa.

Las actuales leyes mexicanas, por ejemplo, aunque consideran como delito al maltrato animal, son especistas porque no protegen a todas las especies de las agresiones que padecen cada día. Al contrario, la legislación favorece y promueve la violencia sistemática contra los demás animales, comenzado por su esclavitud cuando la violencia se normaliza como parte del patrimonio cultural. La propuesta de Ley de Bienestar Animal del 2019, por ejemplo, tiene serios defectos y debe rechazarse. No se trata de una ley de bienestar animal, sino de una ley de uso de los animales. El espíritu de la ley no es el de procurar el bienestar de los animales considerando sus necesidades biológicas, sino que los ve como meros recursos cuyo uso se debe regular.

Finalmente, es necesario remarcar que la idea de patrimonio jamás debe tener un mayor valor que los intereses primarios de cualquier ser sintiente. Para continuar con la tradición del burrocebra, de forma ética, se podrían utilizar burros de fibra de vidrio u otro material, en vez de animales vivos, para que no haya maltrato y que los turistas puedan disfrutar de su fotografía como recuerdo de visitar Tijuana; para el caso de los burros de Otumba, el santuario debería dedicarse sólo al cuidado de los burros sin que exista ningún tipo de exhibición con ellos, es decir, que la finalidad del santuario sea valorar de forma intrínseca a los burros, concientizando a la población que lo visita desde una perspectiva zooética y sin que sean sometidos a eventos recreativos sólo para el deleite de los turistas.

\section{Referencias bibliográficas}

Andrade, J., Moreno, O. y Quiñones, R. (2015). Valoración de atributos culturales e históricos en la imagen promocional de la ciudad de Tijuana como destino turístico. El Periplo Sustentable: revista de turismo, desarrollo y competitividad, (28), 31-58. Recuperado de: https://rperiplo.uaemex.mx/artic le/view/4944

Ángel, D. (2011). La hermenéutica y los métodos de investigación en ciencias sociales. Estudios Filosóficos, 44, 9-37. Recuperado de: https://aprendeenlinea.udea.edu.co/revistas/index.p hp/estudios de filosofia/article/view/12633

Angrosino, M. (2012). Etnografia y observación participante en investigación cualitativa. Madrid: Ediciones Morata

Arluke, A. (2002). Animal abuse as dirty play. Symbolic Interaction, 25(4), 405-430.

Bringas, N. (1991). La participación de la población estadunidense de origen mexicano y anglosajón en la composición de los grupos de visitantes a Tijuana. En Bringas, N. y Carrillo, J. (1991). Grupos de visitantes y actividades turísticas en Tijuana. Tijuana, El Colegio de la Frontera Norte. 47-62.

Buller, H. (2015). Animal geographies II: methods. Progress in Human Geography, 39(3), 374-384.

Cámara de Diputados (2019). Iniciativa de Ley de Bienestar Animal. Cámara de Diputados [En línea]. Versión disponible en: http://www3.diputados.gob.mx/camara/001 _diputados/008_comisioneslx/001_ordinaria s/025_medio_ambiente/020_iniciativa_biene star_animal . Último acceso 23 de noviembre, 2019.

Carmona, R. (2003). Organización territorial del turismo en Tïuana, Baja California. Tesis de licenciatura en Geografía. Facultad de Filosofía y Letras, Universidad Nacional Autónoma de México. $117 \mathrm{p}$.

Carmona, R. y Correa, O. (2008). Estructura territorial del turismo en el corredor Tijuana-RosaritoEnsenada. Teoría y Praxis, (5), 359-375. Recuperado de: https://www.redalyc.org/articulo.oa?id=4561451 10025

Carranza, H. (1999). Monografía Municipal de Otumba. Gobierno del Estado de México, 24 p.

Carrillo, J. y Hualde, A. (2000). Desarrollo regional y maquiladora fronteriza: peculiaridades de un cluster electrónico en Tijuana. El mercado de valores, 60(10), 45-56.

Ceballos, M. (2001). Encuentro en la frontera. Tijuana: El Colegio de México. 
Cháidez, J. (2012). Las Cebras de Tijuana. Leyendas de Tijuana y sus alrededores: mitos, y otras cosas que platica la gente. [En línea]. Versión disponible en: http://leyendasdetijuana.blogsp ot.com/2012/11/las-cebras-detijuana.html\#ixzz4MoeZBovY. Último acces o: 19 de febrero, 2019.

Collard, R., y Gillespie, K. (2015). Introduction. En Critical animal geographies: Politics, intersections, and hierarchies in a multispecies world, editado por Kathryn A. Gillespie y Rosemary-Claire Collard, 1-16. Londres: Routledge.

CONEVAL, (2010). SEDESOL. Informe anual sobre la situación de pobreza y rezago social, Otumba, Estado de México. [En línea]. Versión disponible en: https://www.gob.mx/cms/upl oads/attachment/file/42699/Mexico_065.pd f. Último acceso: 16 de agosto del 2019.

Decrop, A. (1999). Triangulation in qualitative tourism research. Tourism management, 20(1), 157-161.

Donde Hay Feria (2019). Feria Nacional del Burro Otumba 2019. Donde Hay Feria. [En línea]. Versión disponible en: https://www.dondehayferia.com/ferianacional-del-burro-otumba-2019. Último acceso: 19 de agosto del 2019.

Elias, N. (1994). Civilización y violencia. Reis, (65), 141151.

Fennell, D. (2012). Tourism, animals and utilitarianism. Tourism Recreation Research, 37(3), 239-249.

Flores, L. y Terán, C. (2017). Aristóteles y los animales. En Los filósofos ante los animales, editado por Leticia Flores Farfán y Jorge Enrique Linares Salgado. 216-243. Ciudad de México: UNAM/Almadía.

Francione, G. y Garner, R. (2010). The Animal Rights Debate: Abolition or Regulation? Nueva York: Columbia University Press. 288 p.

González, C. y Hiernaux, D. (2015). Patrimonio y centralismo: perspectivas críticas desde el ámbito local. $A, 190,1824-2014$.

Horta, O. (2017). Un paso adelante en defensa de los animales. Madrid: Plaza y Valdés 234 p.

INEGI (2015a). Población en Baja California. [En línea]. Versión disponible en: http://cuentame.inegi.org.mx/monografias/i nformacion/bc/poblacion/ Último acceso 31 de enero, 2020.

INEGI (2015b). Población en Estado de México. [En línea]. Versión disponible en: http://cuentame.inegi.org.mx/monografias/i nformacion/mex/poblacion/. Último acceso 31 de enero, 2020.

Lynn, W. (1998). Animals, Ethics and Geography, en Jennifer Wolch and Jody Emel (eds) Animal Geographies: Place, Politics and Identity in the Nature-Culture Borderlands, Londres: Verso, 280-298.

Martínez, L. y Contreras, D. (2017). La tradición del llamado "burro cebra" genera polémica en Tijuana. Telemundo 20. [En línea]. Versión disponible en: https://www.telemundo20.com/boletinelectronico/noticias/La-tradicion-delllamado-burro-cebra-genera-polemica-enTijuana-445549543.html. Último acceso 19 de abril, 2019.

Massey, D. (1993). Power-geometry and a progressive sense of place. Mapping the futures: local cultures, global change, editado por Tim Putnam, Barry Curtis y Lisa Tickner, 59-69. Londres: Routledge.

Merlo, E. (2016). En abril dirán si burro-cebra sigue como patrimonio cultural de BC. Uniradio [En línea]. Versión disponible en: https://www.uniradioinforma.com/noticias /bajacalifornia/390724/en-abril-diran-siburro-cebra-sigue-como-patrimonio-culturalde-bc.html. Último acceso 1 de mayo, 2019.

Miranda, A. (2018). La tierna historia de Burrolandia del Edomex. Unión Edomex [En línea]. Versión disponible en: http://www.unionedomex.mx/articulo/201 8/07/31/gente/la-tierna-historia-deburrolandia-del-edomex. Último acceso 27 de agosto, 2019.

Mkono, M. (2011). The Othering of Food in Touristic Eatertainment: A Netnography. Tourist Studies, 11, 3, 253-270.

Morales, J. (2016). La leyenda del burro-cebra de Tijuana. Univisión. [En línea]. Versión disponible en https://www.univision.com/local/losangeles-kmex/la-leyenda-del-burro-cebra-detijuana. Último acceso 19 de febrero, 2019.

Newsweek México (2017). El "burro-cebra" podría volver a ser patrimonio cultural de BC. [En línea]. Versión disponible en: https://newsweekespanol.com/2017/09/bur ro-cebra-podria-volver-a-ser-patrimoniocultural-de-bc/. Último acceso 8 de marzo, 2019.

Notimex (2014). Tradición de "burro-cebras" en Tijuana cumple cien años. [En línea]. Versión disponible en:

https://www.publimetro.com.mx/mx/vida/ 2014/08/02/fotos-tradicion-burro-cebrastijuana-cumple-cien-anos.html. Último acceso 8 de marzo, 2019.

Notimex (2015). ONG busca desaparecer en Tijuana a "burros-cebra". El Universal [En línea]. Versión disponible en: https://www.eluniversal.com.mx/articulo/est 
ados/2015/09/12/ong-busca-desapareceren-tijuana-burros-cebra. Último acceso 2 de mayo, 2019.

Observatorio Turístico de Baja California (2015). El burro-cebra de Tijuana: Testigo mudo de la evolución creativa de la ciudad. Secretaría de Turismo del Estado de Baja California. 20 pp.

Ortiz, G. (2018). Ética para matador. Savater, los toros y la ética. Zooética, $85 \mathrm{p}$.

Palaversich, D. (2002). La ciudad que recorro. Un flâneur en Tijuana. Literatura Mexicana, 13(2), 215 - 227. Recuperado de: https://revistas-filologicas.unam.mx/literaturamexicana/index.php/lm/article/view/429

Pata de Perro (2019). Burrolandia México A.C. Proyecto de Rescate del Burrito Mexicano. Pata de Perro. Blog de Viajes [En línea]. Versión disponible https://patadeperro.paulaithurbide.com/viaje s/burrolandia-mexico-a-c-proyecto-derescate-del-burrito-mexicano. Último acceso 27 de agosto, 2019.

Periódico Correo (2018). Celebran la Feria Nacional del Burro en Otumba. [En línea] Versión disponible en:

https://periodicocorreo.com.mx/celebran-laferia-nacional-del-burro-en-otumba/. Ultimo acceso: 15 de agosto, 2019.

Quintero, G. y López Á. (2018). The (unethical) consumption of a newborn animal: cabrito as a tourist and recreational dish in Monterrey, Mexico. En C. Kline (Ed.), Animals, Food, and Tourism (pp. 52-67). Routledge.

Quintero, G. y López, Á. (2020). Geografía de los animales: construcción filosófica de una subdisciplina científica a través de su historia. Cuadernos de Geografia: Revista Colombiana de Geografia, 29(1), 16-31. Recuperado de: https://revistas.unal.edu.co/inde x.php/rcg/article/view/78653

Ramírez, M. (2015). Inauguran estatua del burro en Otumba. Hoy Estado.com [En línea]. Versión disponible

en: https://www.hoyestado.com/2015/04/inaug uran-estatua-del-burro-en-otumba/

Ultimo acceso: 16 de agosto del 2019.

Rebollo, I., Polderman, T. y Moya, L. (2010). Genética de la violencia humana. Revista de neurologia, 50(9), 533-540.

Rotten Tomatoes $(\mathrm{s} / \mathrm{f})$. Tonta Tonta pero no Tanto. Rotten Tomatoes. [En línea]. Versión disponible en: https:/ / www.rottentomatoes.c $\mathrm{om} / \mathrm{m} /$ tonta tonta_pero_no_tanto. Último acceso 19 de agosto, 2019.

Ruiz, J., Martínez, O. y Verján, R. (2015). Valoración de atributos culturales e históricos en la imagen promocional de la ciudad de Tijuana como destino turístico. El Periplo Sustentable: revista de turismo, desarrollo y competitividad, (28), 31-58.

Recuperado de: https://rperiplo.uaemex.mx/artic le/view/4944

Tavera, H. (2016) Otras Naciones. Hacia una teoría de los derechos territoriales de los animales. Pontífica Universidad Católica de Chile, Chile.

Tierney, P. (2000). Internet-based evaluation of tourism web site effectiveness: Methodological issues and survey results. Joumal of Travel Research, 39(2), 212-219.

Tovar, L. (2015). Consentimiento. Filosofía Vegana. [En línea]. Versión disponible en: http:// filosofiavegana.blogspot.com/2015/10 /consentimiento.html. Último acceso $25 \mathrm{de}$ abril, 2019.

Troitiño, M. (1998). Turismo y desarrollo sostenible en ciudades históricas. Ería: Revista cuatrimestral de geografia, (47), 211-228. Recuperado de: https://www.unioviedo.es/reunido /index.php/RCG/article/view/1287

Urbanik, J. (2012). Placing animals: An introduction to the geography of human-animal relations. Rowman \& Littlefield.

Velázquez, A. (2013). La producción política del espacio: el problema de la praxis. Utopía y Praxis Latinoamericana 18 (63):63-74

Vergalito, E. (2009). Acotaciones filosóficas a la 'hermenéutica diatópica' de Boaventura de Sousa Santos. Impulso, 19(48), 19-29. Recuperado de: https://www.metodista.br/revistas Irevistasunimep/index.php/impulso/article/view/98

Vincent, J. (2018). How Zebra-painted Donkeys Became Tijuana's Hottest Tourist Attraction. Culture Trip. [En línea]. Versión disponible en: https://theculturetrip.com/nor th-america/mexico/articles/how-zebrapainted-donkeys-became-tijuanas-hottesttourist-attraction/. Último acceso 19 de febrero, 2019.

Walker, M. (2011). Knowledge production and border nationalism in northern Mexico. Nations and Nationalism, 17(1), 168-187.

Weil, K. (2012). Thinking animals: why animal studies now? Nueva York: Columbia University Press.

\section{Notas}

${ }^{i}$ Gino Jafet Quintero Venegas es actualmente, investigador posdoctoral en la UNAM, becario del Programa Universitario de Bioética, asesorado por la doctora Paulina Rivero Weber. 